\title{
Distinct glucose lowering and beta cell protective effects of vanadium and food restriction in streptozotocin-diabetes
}

\author{
Margaret C Cam, Brian Rodrigues and John H McNeill \\ Division of Pharmacology and Toxicology, Faculty of Pharmaceutical Sciences, The University of British Columbia, Vancouver, British Columbia, \\ Canada V6T 1 Z3
}

(Correspondence should be addressed to J H McNeill, Division of Pharmacology and Toxicology, Faculty of Pharmaceutical Sciences, The University of British Columbia, 2146 East Mall, Vancouver, British Columbia, Canada V6T 1Z3; Email: jmcneill@unixg.ubc.ca)

\begin{abstract}
Vanadium is an oral insulin-mimetic agent that diminishes hyperglycemia, improves beta-cell insulin store and secretory function, and can reverse the diabetic state chronically after withdrawal from treatment. As food restriction has been reported to enhance insulin sensitivity and reduce insulin demand, we assessed the contribution of a reduced food intake to the glucose lowering and beta-cell protective effects of vanadium. Streptozotocin (STZ)-diabetic rats were untreated (D) or administered vanadyl sulfate in the drinking water (DT) at one week prior to and for 5 weeks following the administration of STZ. An additional group was pair-fed (DP) with an equal amount of food as that consumed by the DT group. Shortly after the induction of diabetes, hyperglycemic D rats demonstrated a significant rise in plasma insulin to levels that initially exceeded that of the controls. This was followed by a steady reduction over several weeks, suggesting a gradual depletion of functional beta-cells. Both vanadium treatment and pair-feeding abolished the insulin hypersecretory response following STZ administration. Glucose lowering was enhanced in DT animals when administered higher concentrations of vanadium, despite no further reduction in food intake, and all DT animals (10/10) were normoglycemic by 5 weeks. Mean pancreatic insulin content in DT rats was improved fourfold and was associated with a greater number of granulated beta-cells. Conversely, food restriction only modestly improved glycemia and the pancreatic insulin store and, unlike DT, DP rats remained highly glucoseintolerant. At 5 weeks of diabetes, fed circulating glucose and insulin levels were strongly correlated $(P=0.0002)$ in the $\mathrm{D}$ and DP groups, supporting the notion that glucose lowering with food restriction is dependent on improved plasma insulin levels. A separate correlation was observed in DT animals within a lower range of plasma insulin, suggesting that vanadium, unlike food restriction, reduced plasma glucose by enhancing insulin sensitivity. Thus, vanadium preserves beta-cells in STZ-diabetes at least partially by abolishing the insulin hypersecretory response and the eventual exhaustion of residual insulin stores following a moderate dose of STZ. This property of vanadium would appear to be useful in the treatment of prediabetic and newly diagnosed insulin-dependent diabetes mellitus.
\end{abstract}

European Journal of Endocrinology 141 546-554

\section{Introduction}

Vanadium is a ubiquitous trace element demonstrated to have glucose-lowering properties and improve pancreatic insulin store and secretory function in streptozotocin (STZ)-diabetic rats (1-3). Chronic vanadium treatment also reverses the diabetic state for up to 20 weeks after removal from treatment, a phenomenon associated with increased plasma insulin levels and an enhanced beta-cell mass $(4,5)$. Consequently, we demonstrated that short-term treatment with vanadium prior to and for a short period ( 2 weeks) following the induction of STZ-diabetes eliminated hyperglycemia after withdrawal from treatment (6). Chronic amelioration of the diabetic state in these animals was related to a small but significant increase in the pancreatic insulin store. We had hypothesized that perhaps the removal of hyperglycemia with vanadium treatment had prevented the functional and structural exhaustion of existing beta-cells.

An auxiliary effect of vanadium treatment in both control and diabetic rats is a significant reduction in food intake, suggested to be due to a specific anorexigenic stimulus in the central nervous system (7). Previous studies have reported a similar reduction of hyperglycemia by vanadium treatment and pair-feeding in STZ-diabetic animals $(8,9)$, hence complicating the interpretation of insulin-like properties of vanadium in vivo. In addition, like vanadium, food restriction in STZ-diabetic rats can reduce hyperglycemia and 
increase insulin sensitivity as measured by hyperinsulinemic clamp (10). Chronic food restriction has also been demonstrated to enhance insulin-mediated glucose uptake and reduce insulin demand in control rats (11-13). Furthermore, a significant improvement in insulin sensitivity and delayed progression of loss of endogenous insulin was observed in adult-onset insulindependent diabetes mellitus (IDDM) patients on a normal protein as opposed to a high protein diet (14). Thus, it is plausible that a lowered food intake per se may contribute significantly to both the glucose lowering and beta-cell protective effects of vanadium. In the present study, we compared the effectiveness of chronic vanadium treatment or food restriction on the overall amelioration of the diabetic state. Vanadium treatment or pair-feeding was initiated 1 week prior to the STZ injection in order to acclimatize the animals and to stabilize the level of food intake during and immediately following the administration of STZ.

\section{Materials and methods}

\section{Treatment and maintenance of animals}

Male Wistar rats (170-200g, 7-8 weeks old) were obtained from Charles River (St Constante, Quebec, Canada). The animals were maintained on standard laboratory chow and housed in individual wire-bottom cages. The rats were divided into the following groups: nondiabetic control $(\mathrm{C}, n=4)$, and untreated (D, $n=10)$, vanadyl-treated (DT, $n=10)$, and pair-fed (DP, $n=10)$ diabetic groups. Vanadyl sulfate $(0.75-1.00 \mathrm{mg} / \mathrm{ml}$, Fisher Scientific Co., Fair Lawn, NJ, USA) was provided in the drinking water to the DT group for 7 days prior to STZ injection as described previously (5). In addition, a pair-fed group was provided with the same amount of food as that consumed by the DT group. After 7 days of vanadium treatment or pair-feeding, STZ $(55 \mathrm{mg} / \mathrm{kg}$ i.v., Sigma Chemical Co., St Louis, MO, USA) was administered to the diabetic rats, while the control group received vehicle $(\mathrm{NaCl}, 154 \mathrm{mmol} / \mathrm{l}, \mathrm{pH} 7.2)$. Continuation of vanadium treatment $(1 \mathrm{mg} / \mathrm{ml})$ for 1 week after STZ resulted in normoglycemia in $1 / 10$ DT rats. In an effort to increase the normoglycemic response in the DT group, the concentration of vanadium was gradually raised by increments of $0.25 \mathrm{mg} / \mathrm{ml}$ in all DT animals, to a maximum concentration of $1.75 \mathrm{mg} / \mathrm{ml}$ by 5 weeks. Plasma glucose, insulin, body weight, and daily food and fluid intake were monitored throughout the study. Food intake in DT animals was measured twice daily at $0900 \mathrm{~h}$ and $1800 \mathrm{~h}$ to account for nocturnal and daytime food consumption respectively. The average amount of food consumed was then given to the DP animals at $1800 \mathrm{~h}$ and $0900 \mathrm{~h}$ to mimic the feeding pattern of DT animals. To measure food intake accurately in the DT and DP groups, weighing trays were placed underneath the feed troughs to account for food that had not been consumed.
Animals were killed at 5 weeks post-STZ, and plasma obtained for measuring glucose and triglycerides (Boehringer Mannheim, Laval, Quebec, Canada). Insulin was measured by a radioimmunoassay (RIA) using rat insulin standards (Novo Research Institute, Copenhagen, Denmark), with inter- and intra-assay coefficients of variation of $<10 \%$ and a sensitivity to $7 \mu \mathrm{U} / \mathrm{ml}$ (15).

\section{Oral glucose tolerance test (OGTT)}

At 5 weeks after STZ, all rats were fasted for $16 \mathrm{~h}$ overnight (1800-0900 h). Pair-fed rats were not given their second daily ration of food at $1800 \mathrm{~h}$, hence the last time food had been provided to DP animals prior to the OGTT was at $0900 \mathrm{~h}$ the previous day. The fasted animals were administered glucose $(1 \mathrm{~g} / \mathrm{kg}$ of a $40 \%$ glucose solution) by oral gavage. Blood samples (350 l) were collected from the nicked tail prior to (time 0 ) and at 10, 20, 30 and $60 \mathrm{~min}$ following the glucose dose. Plasma was stored frozen at $-70{ }^{\circ} \mathrm{C}$ for measurement of insulin and glucose levels.

\section{Pancreatic insulin}

At time of death, pancreata were dissected, cleared of lymph nodes and fat, blotted and weighed. The pancreas was immediately homogenized in $5 \mathrm{ml}$ cold $2 \mathrm{M}$ acetic acid for $5 \mathrm{~s}$, and boiled for $10 \mathrm{~min}$. The extract was centrifuged at 15000 r.p.m. for $10 \mathrm{~min}$, and the resulting supernatant was frozen at $-70{ }^{\circ} \mathrm{C}$ until further analysis of insulin.

\section{Islet histology}

A portion of pancreas was fixed in $2 \%$ formalin for $1-2$ days, dried and embedded in paraffin. Sections were stained for granulated beta-cells by the modified aldehyde fuchsin method as previously described (16) and examined by light microscopy.

\section{Vanadium levels}

At termination, kidney, liver, muscle, bone, pancreas and plasma samples were analyzed for vanadium levels via atomic absorption using a method previously described (17).

\section{Statistical analysis}

One-way analysis of variance (ANOVA) was used followed by the Newman-Keuls test. Data are expressed as means \pm S.E.M. $P<0.05$ was considered significant.

\section{Results}

\section{Glycemia and food intake}

Diabetic rats demonstrated a progressive rise in food intake that reached twofold that of control rats by 5 
weeks post-STZ (Fig. 1A). Prior to STZ, vanadium treatment $(1 \mathrm{mg} / \mathrm{ml})$ reduced food intake to $80 \%$ of controls, and this remained unchanged both after the STZ injection and after the vanadium concentration was raised to a maximum of $1.75 \mathrm{mg} / \mathrm{ml}$. However, at higher vanadium concentrations, animals that were previously unresponsive became normoglycemic, such that all $(10 / 10)$ DT rats had normal plasma glucose by week 5 (Fig. 1B). Approximately $1 / 3$ of the total daily food intake in DT animals was consumed between 0900-1800 $\mathrm{h}$ and $\sim 2 / 3$ between 1800-0900 h, and hence pair-fed animals were provided with similar amounts of food during these time intervals. However, unlike the DT animals, pair-fed rats would rapidly consume their entire food ration within the first hour, and hence were fasted for extended periods on a daily basis - from 1100-1800 h $(7 \mathrm{~h})$ and from 1900$0900 \mathrm{~h}(14 \mathrm{~h})$. As blood was routinely collected at 0900-1000 h, plasma glucose and insulin were effectively 14-h fasted values in the pair-fed animals that, nevertheless, remained hyperglycemic. Thus, although mean plasma glucose in the DP group was significantly reduced at week 5, none of these animals developed normoglycemia.

Prior to STZ, vanadium treatment and food restriction for one week reduced body weight gain to
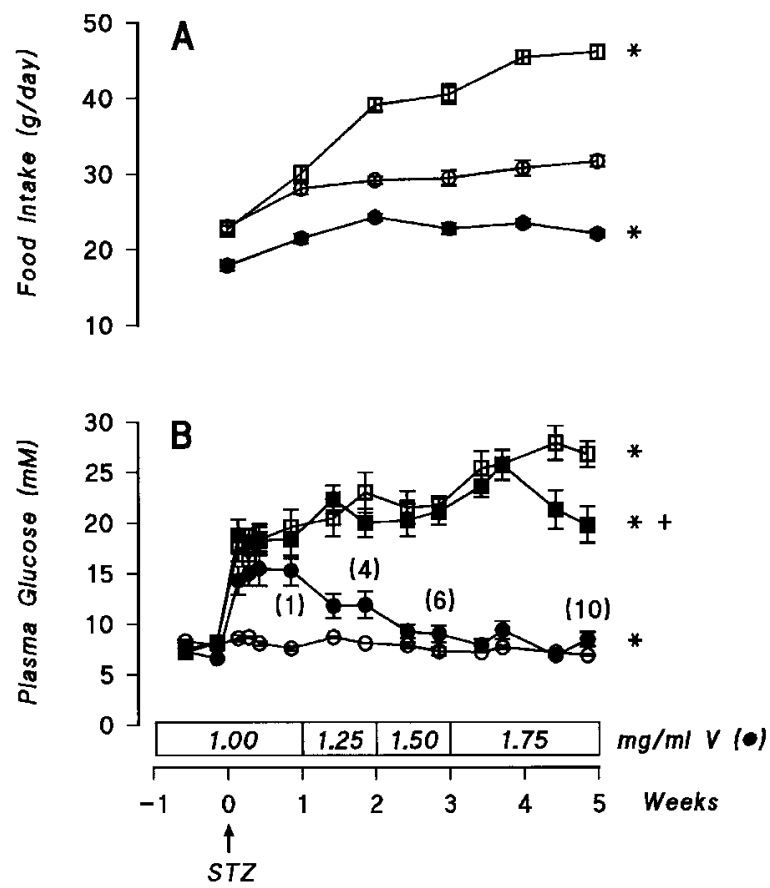

Figure 1 Effects of vanadium treatment and pair-feeding on food intake and plasma glucose levels in STZ-diabetic rats over 6 weeks. Food intake $(A)$ and plasma glucose $(B)$ of control $(C, O)$, and untreated $(D, \square)$, vanadium-treated (DT, - $)$ and pair-fed (DP, diabetic groups over 6 weeks are shown. The numbers of normoglycemic animals in the DT group are shown in parentheses. ${ }^{*} P<0.05$ vs $\mathrm{C},+P<0.05$ vs $\mathrm{D}$. Vanadium (V) concentrations are indicated above the $X$-axis. the same extent (data not shown). However, at 5 weeks after the induction of diabetes, pair-fed animals had a more pronounced reduction in weight gain relative to the DT group (body weight: DP, $246 \pm 8 \mathrm{~g}$ vs DT, $284 \pm 9 \mathrm{~g}, P<0.05)$. Plasma triglyceride levels were also significantly reduced in the DP animals $(0.44 \pm$ $0.05 \mathrm{mmol} / \mathrm{l})$ relative to all other groups (C, $1.20 \pm$ 0.19 ; D, $1.37 \pm 0.32$; DT, $1.25 \pm 0.15 \mathrm{mmol} / \mathrm{l})$.

\section{Oral glucose tolerance test}

After $16 \mathrm{~h}$ of fasting, mean glycemia in DT animals was not significantly different from controls (Fig. 2A). In contrast, and despite having been fasted for $>22 \mathrm{~h}$, DP rats had relatively high basal glucose $(\sim 12 \mathrm{mmol} / \mathrm{l})$ that was not different from the untreated diabetic group. Vanadium-treated rats showed an improved glucose response, with a return to control levels by $60 \mathrm{~min}$, whereas pair-fed rats continued to demonstrate marked glucose intolerance, similar to the D group. The insulin secretory response in all diabetic groups was markedly
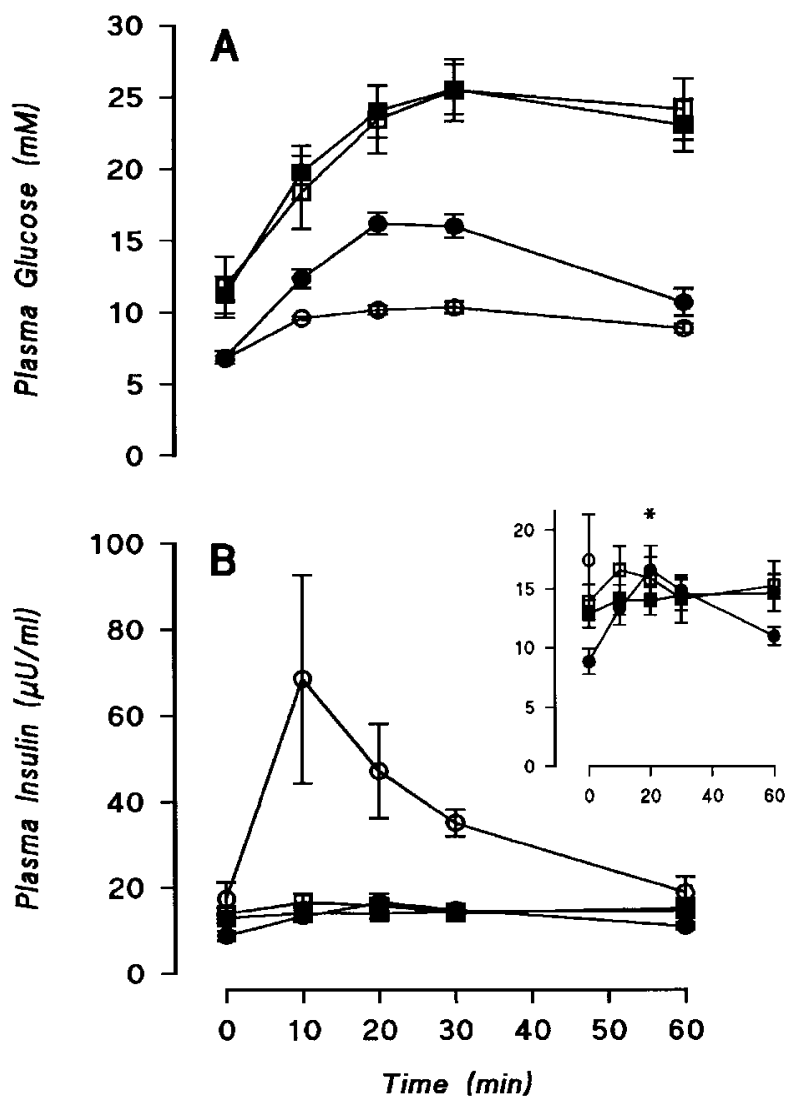

Figure 2 Effect of vanadium treatment and pair-feeding on oral glucose tolerance at 5 weeks. Plasma glucose (A) and insulin (B) responses to $1 \mathrm{~g} / \mathrm{kg}$ oral glucose dose in overnight-fasted rats in control $(C, O)$, and untreated $(D, \square)$, vanadium-treated (DT, $\bullet$ ) and pair-fed (DP, $\mathbf{\square})$ diabetic groups over $60 \mathrm{~min}$ are shown. Inset shows insulin release in enhanced $Y$-axis scale. ${ }^{*} P<0.05$ vs basal. 
reduced relative to control (Fig. 2B). Although no changes over basal insulin were observed in the DP and D groups, DT rats demonstrated a significant peak in insulin (over basal) in response to glucose that returned to basal as glucose levels dropped (Fig. 2B, inset).

\section{Plasma insulin}

Initial plasma insulin levels were similar between control and diabetic animals taken prior to the STZ injection (Fig. 3A). In control rats, plasma insulin was found to increase steadily over 5 weeks, paralleling weight gain $(\sim 200 \mathrm{~g})$ over the same time period. Interestingly, plasma insulin in D animals gradually rose to levels that exceeded that of control animals for 2 weeks following STZ, but subsequently dropped to $50 \%$ of controls by 5 weeks. Prior to the induction of diabetes, plasma insulin was significantly reduced by one week of vanadium treatment but not by pair-feeding. However, both vanadium treatment and pair-feeding abolished the temporal rise in plasma insulin following STZ, and vanadium treatment lowered it to a greater extent than pair-feeding on day 3. Plasma insulin and glucose values (averaged over 4 readings during the final 2 weeks of the study) were strongly correlated $(r=-0.74$, $P=0.0002$ ) in the D and DP groups, but this correlation excluded the DT animals which had both low plasma glucose and insulin levels (Fig. 3B). Nevertheless, the DT group demonstrated a distinct correlation between plasma glucose and insulin levels over a narrower range $(r=-0.68, P=0.03)$ (enhanced $Y$-axis scale, inset). No similar correlation was observed in the control group.

\section{Variable response to vanadium treatment}

As we reported previously (4), some diabetic animals became normoglycemic at relatively low vanadium concentrations (DT-LC, $1.00-1.25 \mathrm{mg} / \mathrm{ml}, n=4$ ) whereas others required higher levels (DT-HC, $1.50-1.75 \mathrm{mg} / \mathrm{ml}$, $n=6)$ to achieve normoglycemia (Fig. 4A). Although plasma glucose levels in the DT-HC subgroup were significantly higher than the DT-LC subgroup for 4 weeks after STZ, plasma insulin levels were equally low over the entire treatment duration in both DT subgroups (Fig. 4B). Although the same concentrations were provided to all DT animals regardless of response, the calculated dose per body weight was significantly greater in the DT-HC subgroup until week 4 because of the higher fluid intake in these animals (Fig. 4C). Fluid intake subsequently dropped as the DT-HC animals gradually responded to treatment. At time of death, vanadium levels $(\mathrm{nmol} / \mathrm{ml}$ or $\mathrm{nmol} / \mathrm{g}$ ) in DT animals

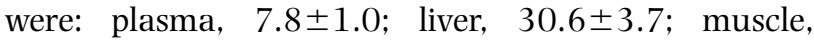
$4.5 \pm 0.2$; pancreas, $8.0 \pm 1.0$; bone, $415.0 \pm 40.4$; kidney, $129.4 \pm 6.9$. These levels are similar to previously reported values in diabetic rats after one year of vanadium treatment (18). Vanadium levels were not
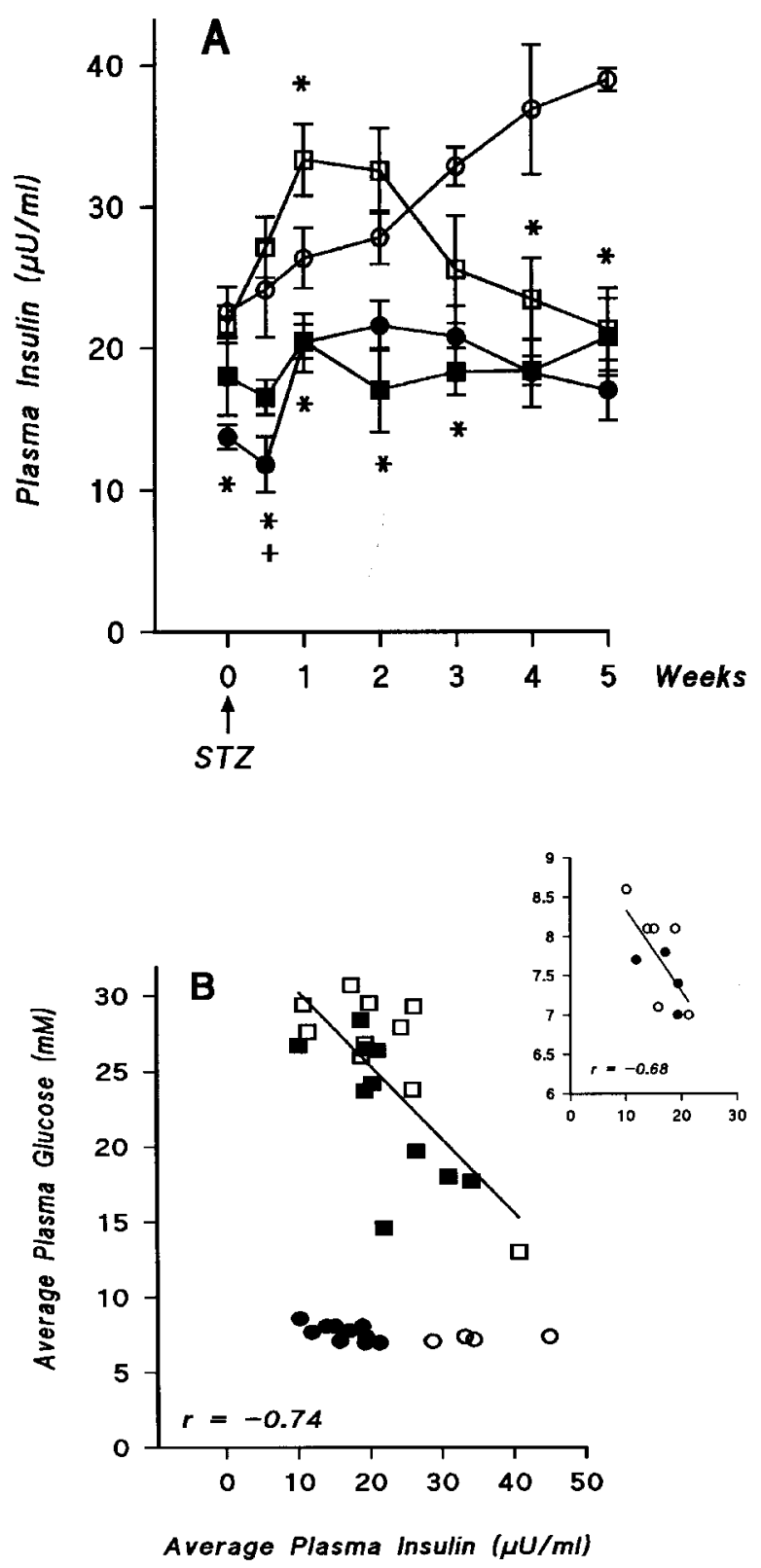

Figure 3 Effect of vanadium treatment and pair-feeding on plasma insulin. Plasma insulin levels (A) and correlation between plasma glucose and insulin levels averaged over 4 readings (final 2 weeks) prior to death $(B)$ in control $(C, O)$, and untreated $(D, \square)$, vanadiumtreated (DT, $\bullet$ ) and pair-fed (DP, $\mathbf{\square})$ diabetic groups. ${ }^{*} P<0.05$ vs $C$, $+P<0.05$ vs DP. Inset shows correlation among DT animals in enhanced $Y$-axis scale.

statistically different between the DT-HC and DT-LC subgroups at 5 weeks.

\section{Pancreatic insulin content and islet histology}

Total pancreatic insulin content was dramatically reduced to $<15 \%$ of controls $(1.6 \pm 0.1 \mathrm{mU} / \mathrm{g})$ in all diabetic rats at 5 weeks after STZ. However, relative to D, 

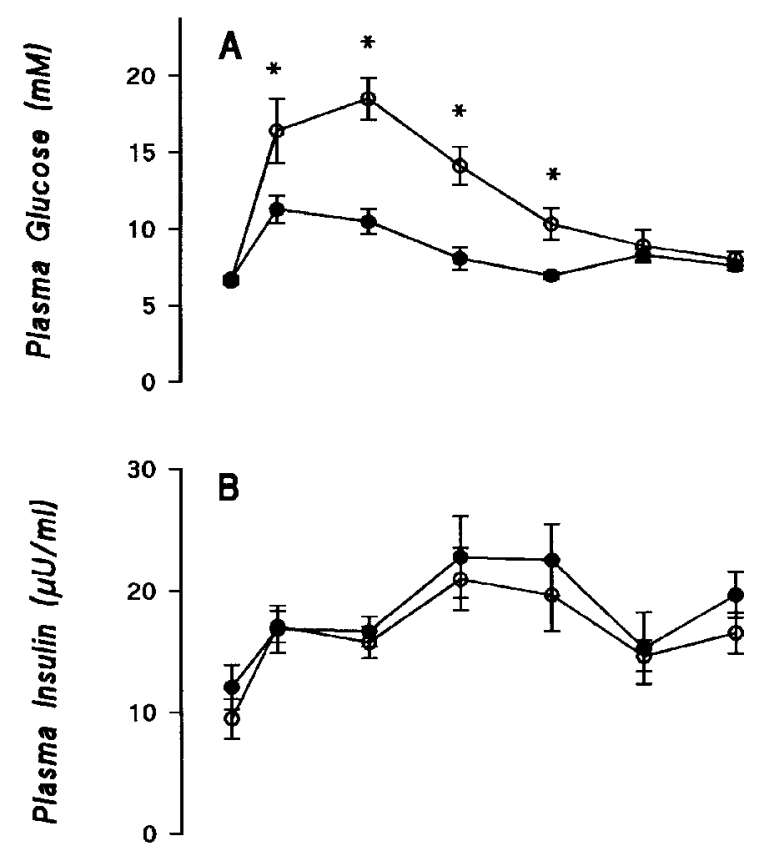

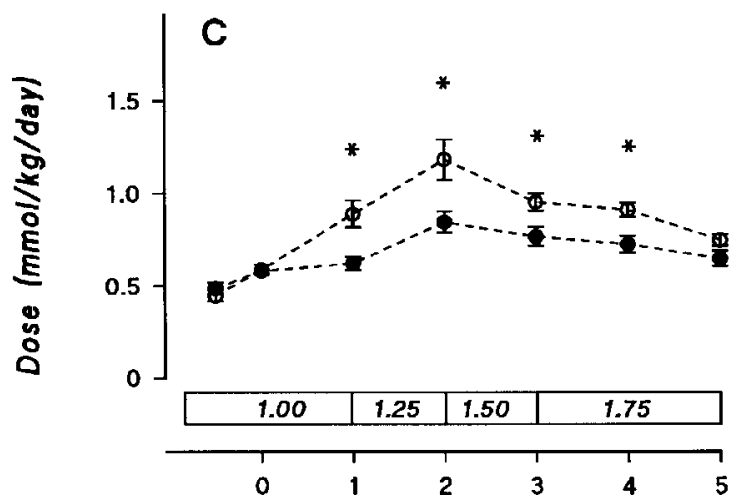

the residual insulin store was higher in DT and DP groups by $\sim 4$ - and 2-fold respectively (Fig. 5A). Within the DT group, those animals that had required low concentrations of vanadium to achieve normoglycemia (DT-LC subgroup) had a residual insulin content that was consistently greater than the DT-HC subgroup that had required higher concentrations of vanadium to achieve normoglycemia. There was a strong correlation between residual insulin store and fed glycemia in the D group ( $r=-0.93, P=0.0003$ ) (Fig. 5B), which was similar to our previous observations in untreated diabetic rats (6). DP animals also demonstrated a strong correlation $(r=-0.88, P=0.0007)$ that was distinct from D, whereas no correlation was found in DT animals. The level of pancreatic insulin store found within the DT-LC subgroup (>150 mU/g) is sufficient for the maintenance of normoglycemia in the absence of vanadium (6). Aldehyde-fuchsin staining revealed that
Figure 4 Plasma glucose, insulin and self-administered vanadium dose in DT subgroups. Fed plasma glucose $(A)$, insulin (B) and vanadium-treated diabetic animals showing subgroups normalized at low (DT-LC, $1.00-1.25 \mathrm{mg} / \mathrm{ml}, \bullet, n=4)$ and high (DT-HC, $1.50-1.75 \mathrm{mg} / \mathrm{ml}, \mathrm{O}$, $n=6$ ) concentrations of vanadyl sulfate in the drinking water (indicated above the $X$-axis). ${ }^{*} P<0.05$ vs DT-LC. the beta-cells in islets of control animals were well granulated (Fig. 6A), whereas those from the untreated (Fig. 6B) and pair-fed (Fig. 6D) diabetic groups were degranulated. The vanadium-treated animals consistently showed a greater degree of beta-cell granulation relative to the other diabetic groups (Fig. 6C).

\section{Discussion}

Pharmacological interventions that effectively stabilize a functional beta-cell mass at the onset of Type 1 diabetes have been shown to induce a chronic amelioration of the diabetic state (19). In rats, pretreatment with exogenous insulin for 5 days offset the diabetogenic action of STZ by preserving 30\% of the pancreatic insulin content, an effect attributed to a reduced activity of beta-cells at the time of STZ administration (20). In contrast, increased metabolic 

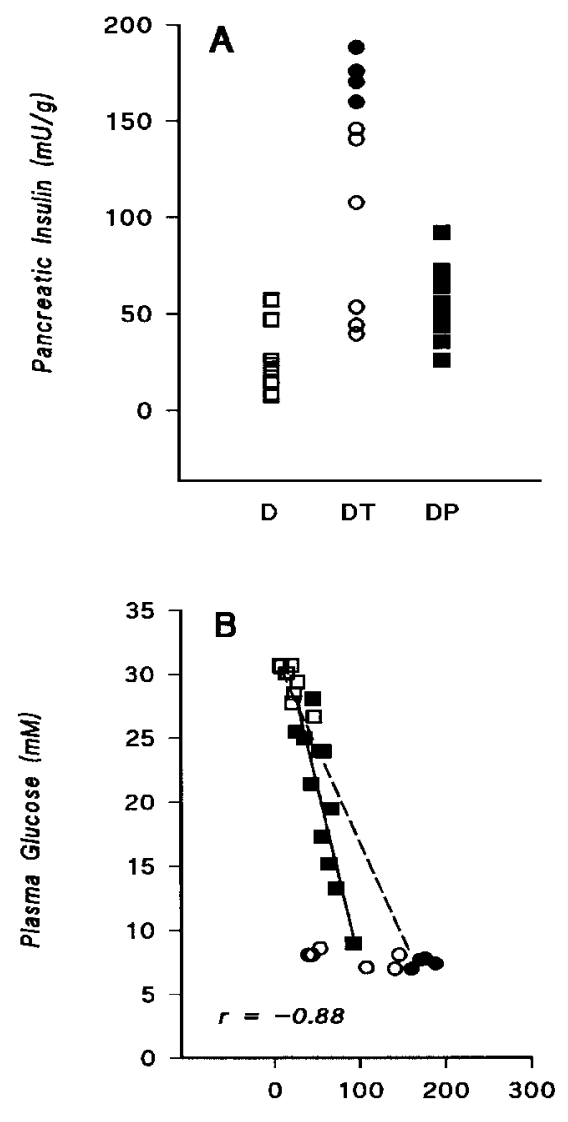

Pancreatic Insulin $(\mathrm{mU} / \mathrm{g})$

Figure 5 Pancreatic insulin content. (A) Pancreatic insulin content and $(B)$ correlation with plasma glucose levels in the various diabetic groups: untreated ( $\square$ ), treated (DT) rats normalized following low (DT-LC, 1.00-1.25 mg/ml, ) and high (DT-HC, 1.50 $1.75 \mathrm{mg} / \mathrm{ml}$, O) vanadyl concentrations and pair-fed ( $\square$ ) groups. Dashed line represents correlation in the untreated D group.

activity by incubating at high glucose concentration enhanced susceptibility of beta-cells to STZ (21). We have previously demonstrated that vanadium treatment can induce a chronic reversal of the diabetic state long after treatment is ceased, an effect linked to improvements in both pancreatic insulin store and secretory function $(4,5)$. Consequently, we found that, whereas 1 -week vanadium pretreatment did not prevent the onset of diabetes, continued treatment for 2 weeks after STZ effectively reversed the diabetic state in $50 \%$ of the animals (6). Thus, the protection of beta-cells by vanadium cannot be due to its effects at the time of STZ administration, but more likely depends on events following the induction of diabetes. In this respect, short-term insulin treatment following STZ in neonatal rats was also found to enhance the spontaneous remission of diabetes (22). In humans, intensive insulin treatment for 2 weeks following recent-onset diabetes results in the preservation of residual beta cell function and insulin content for at least one year $(23,24)$. This effect was attributed to a reduced insulin demand, as direct inhibition of insulin secretion by diazoxide also preserved beta cells in Type 1 diabetic patients (25), and reduced the incidence of diabetes in spontaneously diabetic BB (26) and 90\% pancreatectomized rats (27).

In this study, untreated diabetic animals experienced a surge in circulating insulin levels for 2 weeks following STZ, indicating that residual, viable beta cells had maintained some insulin secretory function. A subsequent decline in insulin levels over several weeks suggests a gradual depletion of the residual insulin store that was $<5 \%$ at 5 weeks. These observations are consistent with a study by Junod et al. who demonstrated that, following a moderate dose of STZ $(55 \mathrm{mg} /$ $\mathrm{kg}$ ), the residual insulin reserve was further depleted to $<5 \%$ of control by 4 weeks (28). The high circulating insulin following STZ may have resulted from a sustained compensatory response of the remaining beta cells to the prevailing hyperglycemia. On the other hand, Leahy et al. (29) reported that 90\% pancreatectomized rats had beta-cells that were intrinsically more sensitive to glucose and secreted insulin at $90 \%$ of their capacity, leading to a loss of glucoseinduced insulin secretion. Both vanadium treatment and food restriction effectively abolished the temporal insulin hypersecretory phase following STZ, and resulted in significantly improved insulin stores. Hence, it appears that vanadium and, to a lesser extent, food restriction may have preserved the residual beta-cell mass by preventing its gradual exhaustion.

Vanadium has been reported to reduce plasma insulin levels in animals that exhibit hyperinsulinemia such as obese $f a / f a$ (30), spontaneously hypertensive (31) and fructose-hypertensive (32) rats. Notably, administration of vanadate to hyperinsulinemic $o b / o b$ mice reduced plasma insulin levels, which led to a fourfold improvement in insulin stores by 7 weeks (33). In this study, the apparent inhibition of insulin secretion by vanadium was not secondary to its glucose lowering effect as both DT-LC and DT-HC animals experienced a similar reduction in circulating insulin despite markedly different levels of glycemia. This suggests that vanadium can exert a direct inhibitory effect on insulin secretion in pancreatic beta-cells. High concentrations of vanadium $(0.1-1 \mathrm{mmol} / \mathrm{l})$ in vitro have been shown to stimulate insulin secretion from rat islets $(34,35)$. However, inhibition of glucose-stimulated insulin release was demonstrated at vanadium levels $(<10$ $\mu \mathrm{mol} / \mathrm{l})$ similar to those detected in plasma and pancreas both in this and in previous studies (36). Aside from a sustained inhibitory effect on insulin release, it is also possible that normalization of glucose levels per se (for instance, by administering phlorizin) could reduce functional demand and result in the partial protection of beta-cells. Interestingly, several elements that were found to have glucose-lowering properties in STZ-diabetic rats, such as molybdenum, selenium and tungsten, were similarly shown to 

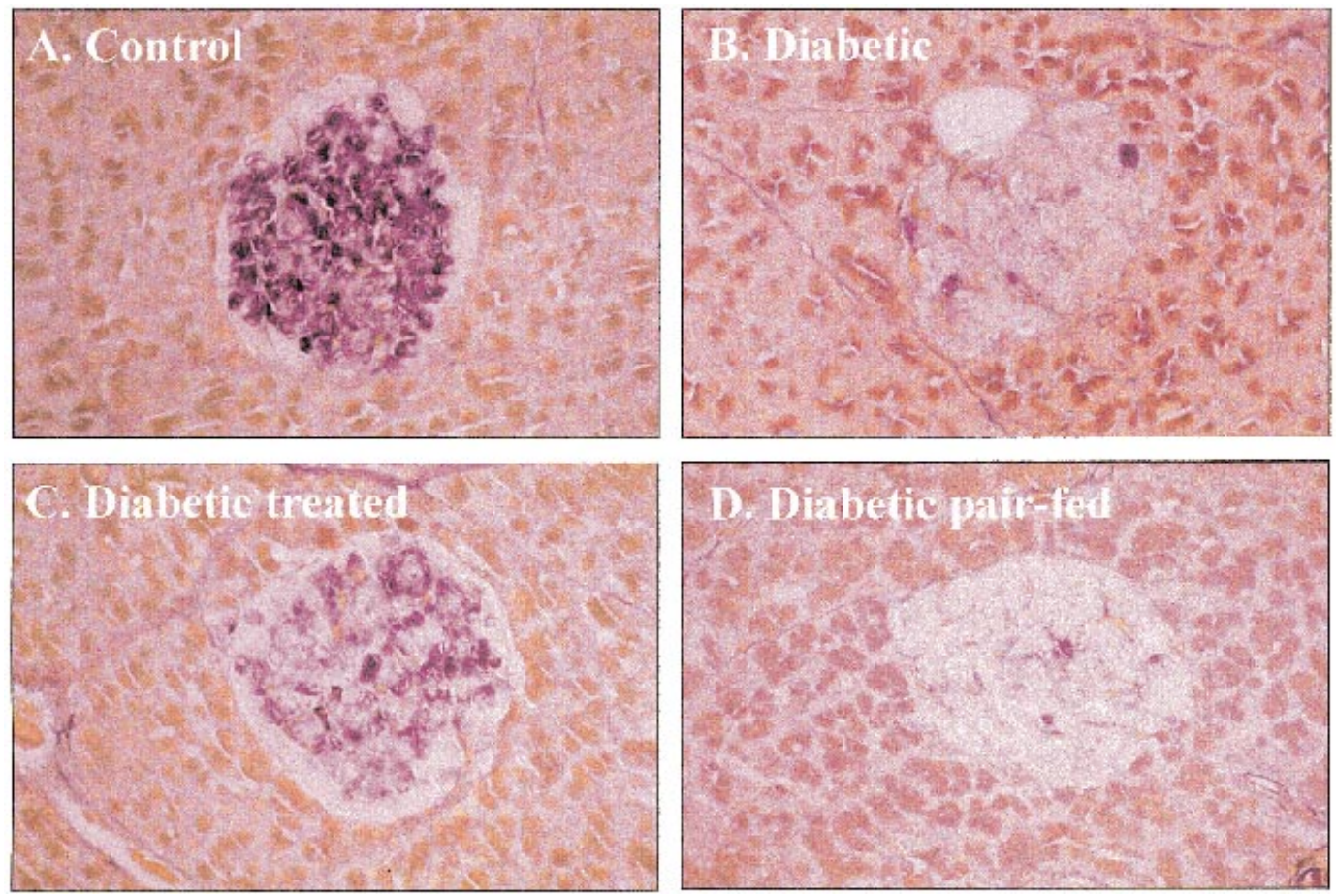

Figure 6 Islet histology. Photomicrographs of islets stained for beta-cells in control (A), and in diabetic untreated (B), vanadium-treated (C) and pair-fed (D) groups. Original magnification $\times 500$.

induce slight to significant increases in insulin store or glucose-stimulated insulin secretion (37-39). Furthermore, tungsten increased the incorporation of $\left[{ }^{3} \mathrm{H}\right]$ thymidine to islet cell lines, suggesting a direct trophic effect (39). Whether vanadium or the other elements have direct positive effects on beta-cell function, either by enhancing beta-cell regeneration or by increasing insulin gene expression, requires further study.

The degree of beta-cell protection afforded by vanadium, to the extent that some treated animals experience a chronic reversal of the diabetic state, may depend on the relative number of beta cells that initially survived destruction by STZ. Thus, more severely diabetic animals that had required higher concentrations of vanadium to achieve normoglycemia were also more likely to revert to hyperglycemia once treatment was withdrawn, whereas those requiring relatively lower doses remained normoglycemic for 5 months after removal of vanadium (4). In this regard, insulin treatment for 7 days following the administration of STZ normalized islet morphology and insulin secretory response and reversed the diabetic state for 3 months following moderate $(50 \mathrm{mg} / \mathrm{kg})$ but not high $(60-$ $70 \mathrm{mg} / \mathrm{kg}$ ) doses of STZ (22). Similarly, following a high STZ dose $(75 \mathrm{mg} / \mathrm{kg})$, hyperglycemia recurred in all animals after vanadium treatment was withdrawn (40). It is notable in this study that the more responsive DT-LC animals were also ones that maintained a critical level of pancreatic insulin store $(150 \mathrm{mU} / \mathrm{g})$ previously found to support normoglycemia per se (6), and hence can be predicted to remain normal had treatment been withdrawn. Although food restriction similarly reduced plasma insulin levels throughout the entire study, the relative improvement in residual insulin store in DP animals was still less than that resulting from vanadium treatment. It should be noted that blood was collected at a time when pair-fed animals had been without available food for at least $14 \mathrm{~h}$, and that plasma insulin levels could have been consistently higher during the time of feeding. Additionally, plasma insulin in the DT group was significantly lower than the pair-fed group at 3 days after STZ. As the residual insulin store in DP rats remained well below the critical level required to support normoglycemia per se, it is likely that the moderate lowering of plasma glucose observed in some pair-fed animals would have been reversed had normal (food available ad libitum) feeding resumed.

Recent studies indicate that food restriction has no beneficial effect on hepatic glucose metabolism (38) or cardiac dysfunction (41) in STZ-diabetic rats. Moreover, as vanadium was demonstrated to have acute (within minutes) glucose lowering effects (42), this would rule out the contribution of a reduced food intake to explain its hypoglycemic action. This study also confirms that the glucose lowering effects due to vanadium are separate from those of a reduced food intake $(8,9)$. First, an enhanced glucose lowering response with higher vanadium doses did not accompany a further 
reduction in food intake. In addition, effects of a reduced food intake on glycemia were relatively modest compared with the dramatic reduction in response to vanadium treatment, and DP rats remained highly glucose-intolerant. Finally, unlike pair-fed and untreated diabetic rats that showed a strong correlation between glycemia and insulin (both plasma and pancreatic), normoglycemia induced by vanadium treatment did not necessitate an increased availability of insulin. Notably, 3 DT rats had pancreatic insulin content $<60 \mathrm{mU} / \mathrm{g}$, levels that did not support normoglycemia in either D or DP rats. This notion of a complementary action between vanadium and insulin is inherent in the observation that more severely diabetic animals, which had a lower residual pancreatic insulin content at 5 weeks, also required higher concentrations of vanadium to achieve normoglycemia. However, although the effectiveness of vanadium is initially dependent on the residual insulin stores, when administered at higher concentrations it can elicit normoglycemia even in animals with insulin stores as low as $2.5 \%$ of control. As beta-cell function in STZ-diabetes is very closely correlated with pancreatic insulin content and intercepts at zero (43), it would mean that vanadium could continue to exert its glucose lowering effects even when pancreatic secretory function is severely diminished.

A possible explanation for the dramatic reduction in glucose levels by food restriction in previous studies $(8$, 9) was that sporadic feeding produced prolonged periods of starvation. Despite feeding these animals at two intervals per day, plasma glucose levels actually represented 14-h fasted values as DP rats consumed all their food within $1 \mathrm{~h}$. In comparison, previous studies using a once-daily feeding schedule would probably have measured glucose levels following an even longer period of fasting. Indeed, in an earlier report by the same group, food-restricted diabetic rats rapidly consumed the available food (44). Thus, as bleeding was routinely carried out at $0900 \mathrm{~h}$, pair-fed diabetic rats were probably fasted for at least $22 \mathrm{~h}$ after having been fed at $0900 \mathrm{~h}$ the previous day (9). Thus, the dramatic reduction in glycemia induced by food restriction in diabetic rats can arise from poorly controlled feeding which, in conjunction with the hyperphagic behavior of diabetic rats, results in prolonged fasting.

In summary, vanadium preserves beta-cells in STZdiabetes at least in part by preventing the beta-cell hypersecretory response and exhaustion of residual insulin stores following a moderate dose of STZ. In this way, short-term treatment with vanadium can reverse the diabetic state by preserving a small, albeit critical, amount of insulin store that adequately supports normoglycemia even after long-term withdrawal from treatment. This inhibitory effect of vanadium on insulin secretion is not dependent on a reduction of plasma glucose levels, and might be a direct effect on beta-cells. In addition, we show that the glucose-lowering effect of vanadium is not dependent on an increased availability of plasma or pancreatic insulin as observed in pair-fed animals, thus ruling out the notion that a reduced food intake contributes significantly to the amelioration of diabetes by vanadium. Hence, the combined effects of vanadium in eliciting normoglycemia at remarkably low insulin reserves and in preserving residual insulin stores suggests that it may prevent the progressive deterioration of beta-cells in prediabetic and newly diagnosed IDDM.

\section{Acknowledgements}

This study was supported financially by the Medical Research Council of Canada. The authors acknowledge Dr Gerard Cros for the measurement of tissue vanadium levels and Erika Vera, Wai-Ming Li, Violet Yuen, Karen Gilchrist and Christopher Savage for their technical assistance.

\section{References}

1 Blondel O, Bailbe D \& Portha B. In vivo insulin resistance in streptozotocin-diabetic rats - evidence for reversal following oral vanadate treatment. Diabetologia 32 185-190.

2 Brichard SM, Okitolonda W \& Henquin JC. Long term improvement of glucose homeostasis by vanadate treatment in diabetic rats. Endocrinology $19881232048-2053$.

3 Cam MC, Pederson RA, Brownsey RW \& McNeill JH. Long-term effectiveness of oral vanadyl sulphate in streptozotocin-diabetic rats. Diabetologia 199336 218-224.

4 Cam MC, Faun J \& McNeill JH. Concentration-dependent glucoselowering effects of oral vanadyl are maintained following treatment withdrawal in streptozotocin-diabetic rats. Metabolism $199544332-339$.

5 Pederson RA, Ramanadham S, Buchan AMJ \& McNeill JH. Longterm effects of vanadyl treatment on streptozotocin-induced diabetes in rats. Diabetes 198928 1390-1395.

6 Cam MC, Li WM \& McNeill JH. Partial preservation of pancreatic $\beta$-cells by vanadium: evidence for a mechanism of chronic amelioration of diabetes. Metabolism 199746 769-778.

7 Meyerovitch J, Shechter Y \& Amir S. Vanadate stimulates in vivo glucose uptake in brain and arrests food intake and body weight gain in rats. Physiology and Behavior 198945 1113-1116.

8 Malabu UH, Dryden S, McCarthy D, Kilpatrick A \& Williams G. Effects of chronic vanadate administration in the STZ-induced diabetic rat. The anti-hyperglycemic action of vanadate is attributable entirely to its suppression of feeding. Diabetes 1994 $439-15$.

9 Domingo JL, Gomez M, Sanchez DJ, Llobet JM, Corbella J \& Keen CL. Normalization of hyperglycemia by vanadate or vanadyl treatment in diabetic rats: pharmacological and toxicological aspects. Trace Elements in Medicine 199411 16-22.

10 Cameron-Smith D, Collier GR \& O'Dea K. Reduction in hyperglycemia by mild food restriction in streptozotocin-induced diabetic rats improves insulin sensitivity. Hormone and Metabolic Research 199426 316-321.

11 Chu KU, Ishizuka J, Poston GJ, Townsend CM, Greeley GH, Yu BP et al. Change in endocrine pancreatic function in short-term diet restriction. Nutrition $19917425-429$.

12 Escriva F, Rodriguez C, Cacho J, Alvarez C, Portha B \& PascualLeone AM. Glucose utilization and insulin action in adult rats submitted to prolonged food restriction. American Journal of Physiology 1992263 E1-E7.

13 Picarelblanchot F, Alvarez C, Bailbe D, Pascualleone AM \& Portha B. Changes in insulin action and insulin secretion in the rat after 
dietary restriction early in life - influence of food restriction versus low-protein food restriction. Metabolism 199544 15191526.

14 Linn T, Geyer R, Prassek S \& Laube H. Effect of dietary protein intake on insulin secretion and glucose metabolism in insulindependent diabetes mellitus. Journal of Clinical Endocrinology and Metabolism 199681 3938-3943.

15 Cam MC \& McNeill JH. A sensitive radioimmunoassay optimized for reproducible measurement of rat plasma insulin. Journal of Pharmacological and Toxicological Methods 199635 111-119.

16 Mowry RW, Longley GB \& Emmel VM. Only aldehyde-fuchsin made from pararosanilin stains pancreatic $\beta$-cell granules and elastic fibers in unoxidized microsection: problems caused by mislabeling of certain basic fuchsins. Stain Technology 198055 91-103.

17 Mongold JJ, Cros GH, Vian L, Tep A, Ramanadham S, Siou G et al. Toxicological aspects of vanadyl sulphate on diabetic rats: effects on vanadium levels and pancreatic $\beta$-cell morphology. Pharmacology and Toxicology $199067192-198$.

18 Dai, S, Thompson KH, Vera E \& McNeill JH. Toxicity studies on one-year treatment of non-diabetic and streptozotocin-diabetic rats with vanadyl sulphate. Pharmacology and Toxicology 199475 265-273.

19 Elliott JF. New approaches to preventing and treating Type 1 diabetes: discovering a method to preserve $\beta$ cell mass after diagnosis should remain a key research focus. Canadian Journal of Diabetes Care 199822 S24-S30.

20 Thulesen J, Orskov C, Holst JJ, Seier S \& Poulsen S. Short term insulin treatment prevents the diabetogenic action of streptozotocin in rats. Endocrinology $199713862-68$.

21 Eizirik DL, Strandell E \& Sandler S. Culture of mouse pancreatic islets in different glucose concentrations modifies $\beta$ cell sensitivity to streptozotocin. Diabetologia 198831 168-174.

22 Ar'Rajab A \& Ahren B. Long-term diabetogenic effect of streptozotocin in rats. Pancreas 19938 51-57.

23 Schnell O, Eisfelder B, Standl E \& Ziegler AG. High-dose intravenous insulin infusion versus intensive insulin treatment in newly diagnosed IDDM. Diabetes 199746 1607-1611.

24 Shah SC, Malone JI \& Simpson NE. A randomized trial of intensive insulin therapy in newly diagnosed insulin-dependent diabetes mellitus. New England Journal of Medicine 1989320 550-554.

25 Bjork E, Berne C, Kampe O, Wibell L, Oskarsson P \& Karlsson FA. Diazoxide treatment at onset preserves residual insulin secretion in adults with autoimmune diabetes. Diabetes $1996451427-1431$

26 Vlahos WD, Seemayer TA \& Yale JF. Diabetes prevention in BB rats by inhibition of endogenous insulin secretion. Metabolism 1991 $40825-829$.

27 Leahy JL, Bumbalo LM \& Chen C. Diazoxide causes recovery of $\beta$-cell glucose responsiveness in $90 \%$ pancreatectomized diabetic rats. Diabetes $199443173-179$.

28 Junod A, Lambert AE, Stauffacher W \& Renold AE. Diabetogenic action of streptozotocin: relationship of dose to metabolic response. Journal of Clinical Investigation 196948 2129-2139.

29 Leahy JL, Bumbalo LM \& Chen C. Beta-cell hypersensitivity for glucose precedes loss of glucose-induced insulin secretion in $90 \%$ pancreatectomized rats. Diabetologia 199336 1238-1244.
30 Brichard SM, Pottier AM \& Henquin JC. Long-term improvement of glucose homeostasis by vanadate in obese hyperinsulinemic fa/fa rats. Endocrinology 1989124 2510-2516.

31 Bhanot S, Bryer-Ash M, Cheung A \& McNeill JH. Bis(maltolato)oxovanadium(IV) attenuates hyperinsulinemia and hypertension in spontaneously hypertensive rats. Diabetes $199443857-$ 861.

32 Bhanot S, McNeill JH \& Bryer-Ash M. Vanadyl sulfate prevents fructose-induced hyperinsulinemia and hypertension in rats. Hypertension 199423 308-312.

33 Brichard SM, Bailey CJ \& Henquin JC. Marked improvement of glucose homeostasis in diabetic ob/ob mice given oral vanadate. Diabetes $1990391326-1332$.

34 Fagin JA, Ikejiri K \& Levin SR. Insulinotropic effects of vanadate. Diabetes 198736 1448-1452.

35 Zhang A, Gao ZY, Gilon P, Nenquin M, Drews G \& Henquin JC. Vanadate stimulation of insulin release in normal mouse islets. Journal of Biological Chemistry 1991266 21649-21656.

36 Voss C, Herrmann I, Hartmann K \& Zuhlke H. In vitro effect of vanadate on content, secretion and biosynthesis of insulin in isolated islets of normal Wistar rats. Experimental and Clinical Endocrinology 199299 159-163.

37 Ozcelikay AT, Becker DJ, Ongemba LN, Pottier AM, Henquin JC \& Brichard SM. Improvement of glucose and lipid metabolism in diabetic rats treated with molybdate. American Journal of Physiology 1996270 E344-E352.

38 Becker DJ, Reul B, Ozcelikay AT, Buchet JP, Henquin JC \& Brichard SM. Oral selenate improves glucose homeostasis and partly reverses abnormal expression of liver glycolytic and gluconeogenic enzymes in diabetic rats. Diabetologia 199639 3-11.

39 Barbera A, Fernandez-Alvarez J, Truc A, Gomis R \& Guinovart JJ. Effects of tungstate in neonatally streptozotocin-induced diabetic rats: mechanism leading to normalization of glycemia. Diabetologia 199740 143-149.

40 Bendayan M \& Gringas D. Effect of vanadate administration on blood glucose and insulin levels as well as on the exocrine pancreatic function in streptozotocin-diabetic rats. Diabetologia $198932561-567$.

41 Yuen, VG, Orvig C \& McNeill JH. Effects of bis(maltolato)oxovanadium(IV) are distinct from food restriction in STZ-diabetic rats. American Journal of Physiology 1997272 E30-E35.

42 Yuen VG, Orvig C \& McNeill JH. Comparison of the glucoselowering properties of vanadyl sulfate and bis(maltolato)oxovanadium(IV) following acute and chronic administration. Canadian Journal of Physiology and Pharmacology 199473 55-64.

43 McCulloch DK, Koerker DJ, Kahn SE, Bonner-Weir S \& Palmer JP. Correlations of in vivo beta-cell function tests with beta-cell mass and pancreatic insulin content in streptozotocin-administered baboons. Diabetes $199140673-679$.

44 McKibbin PE, McCarthy HD, Shaw P \& Williams G. Insulin deficiency is a specific stimulus to hypothalamic neuropeptide Y: a comparison of the effects of insulin replacement and food restriction in streptozocin-diabetic rats. Peptides 199213 721-727.

Received 29 March 1999

Accepted 12 July 1999 